\title{
THERMAL PLASMA SYNTHESIS OF NANO-SIZED POWDERS
}

\author{
JUN-HO SEO and BONG-GUEN HONG* \\ High Enthalpy Plasma Research Center, Chonbuk National University \\ Jeonbuk, 561-756, Korea \\ ${ }^{*}$ Corresponding author. E-mail : bghong@jbnu.ac.kr
}

Received January 26, 2012

\begin{abstract}
A brief review on the thermal plasma synthesis of nano-sized powders is presented according to the application materials, such as, metals, ceramics, glasses, carbonaceous materials and other functional composites, such as, supported metal catalyst and core-shell structured nano materials. As widely adopted plasma sources available for thermal plasma synthesis of nanosized powders, three kinds of plasma torches, such as transferred and non-transferred DC and RF plasma torches, are introduced with the main features of each torch system. In the basis of the described torch features and the properties of suggested materials, application results including synthesis mechanism are reviewed in this paper.
\end{abstract}

KEYWORDS : Thermal Plasma, Torch, Nano Powder, In-flight, Arc Discharge

\section{INTRODUCTION}

Thermal plasmas, normally generated by DC (direct current) arc or inductively coupled RF (Radio Frequency) discharge, can be described as a high enthalpy flame with extremely high temperature fields $(1,000 \sim 20,000 \mathrm{~K})$ and a wide range of velocity fields from several $\mathrm{m} / \mathrm{s}$ [1-5] to supersonic values [6-7]. Since the resultant huge enthalpy can be realized for various kinds of plasma forming gases and easily controlled by electricity, thermal plasmas have been expected to facilitate not only fast chemical reactions but also rapid heat transfer in a variety of synthetic routes for nano-sized materials [8-11]. For example, reactive gases, such as, nitrogen and oxygen, can be chemically activated in the form of various radicals dissociated or ionized in their thermal plasma state. As reported in many other papers [8-10], these radicals can be directly used in the formation of nitrides and oxides with very small sizes. Moreover, many kinds of micron-sized solid precursors can be immediately heated up to their evaporation points when they are injected into thermal plasma flames. In this case, nano-sized particles can also be synthesized by quenching those vapors as shown in Fig. 1. These features of thermal plasmas available for the synthesis of nano-sized materials, however, vary depending on the employed plasma torches $[9,11]$. For example, non-transferred DC torches with hot cathodes normally produce a hot ionized flame with temperatures in the range of $8,000 \sim 16,000 \mathrm{~K}$ at the torch exit [2]. The velocities of this flame can reach to hundreds $\mathrm{m} / \mathrm{s}$ or to several thousand $\mathrm{m} / \mathrm{s}$ depending on the torch nozzle structures at a given gas flow rate [2,12-14]. On the other hand, RF plasma torches produce relatively large flame of 5,000 10,000 K moving at mild velocities of up to several tens $\mathrm{m} / \mathrm{s}[2,5,15-17]$. In addition, the absence of electrodes may be favorable for the formation of reactive thermal plasma. Hence, actual synthesis systems have adopted plasma torches, maximizing their unique features, such as, flow fields, flame sizes, and torch structure itself, to the targeted nano materials. Among the torches adopted in this way, three kinds of plasma torches are illustrated in Fig. 2 as the typical plasma sources available for synthesis of nano-sized materials. Since the characteristics of these torches have been intensively studied with the main features of the generated thermal plasmas [1 5], we will address a brief review on their application results to various materials in this paper, such as, metals, ceramics, glasses, carbonaceous materials and other functional composites like metal-oxide catalysts and core-shell structured nano-materials.

\section{THERMAL PLASMA SYNTHESIS OF NANO- SIZED METAL POWDERS}

Many interesting properties have been found in metal particles with the sizes of $<50 \mathrm{~nm}$. For example, gold metals show the decrease of melting points from $1,337 \mathrm{~K}$ for bulk to $600 \mathrm{~K}$ for small particles having diameters of $2 \mathrm{~nm}$ [18]. In addition, optical properties of gold are also changed when their diameters are reduced down to $<50 \mathrm{~nm}$ 
[19]. For most kinds of metals with sizes of $<50 \mathrm{~nm}$, similar changes may take a place due to the size effect on their properties [20]. However, their practical applications are now limited because they are still expensive and difficult to mass production. In contrast, metal powders with relatively large sizes of $50 \sim 500 \mathrm{~nm}$ are increasingly in demand in various industries as the alternatives to conventional micron-sized ones. For example, Ni powders with sizes of $50 \sim 200 \mathrm{~nm}$ are very promising as the attractive electrode materials in high performance MLCC (Multi-Layered Ceramic Capacitor) [21]. For this reason, our review will be focused on the efforts to prepare metal powders with the sizes of $50 \sim 500 \mathrm{~nm}$ using thermal plasmas.

In recent decades, transferred DC plasma torches as shown in Fig. 2 (a) have been widely employed as an effective heat source [22-25] for the production of nano metal powders with sizes around $50 \mathrm{~nm}$. Since the target metals are used as electrodes in this type of plasma torch, the transferred arc plasma evaporates the electrode materials directly. Accordingly, nano-sized powders can be easily obtained from most kinds of metals by means of transferred DC plasma torch. For the same reason, however, the rate of generating nano-sized metal particles is strongly dependent on physical properties of metals used as electrode target. For example, S. Ohno et.al.'s [22] have recorded the generation rate of nano-sized particles for 16 metals as follow: Mn (64.2) $>\mathrm{Ag}(10.1)$ $>\mathrm{Al}(8.7)>\mathrm{Sc}(6.3)>\mathrm{Cr}(5.9)>\mathrm{Si}(1.3)>\mathrm{Pd}(1.1)>\mathrm{Fe}$ $(1.0)>\mathrm{Cu}(0.8)>\mathrm{Co}(0.7)>\mathrm{Ti}(0.5)>\mathrm{Ni}(0.3)>\mathrm{V}(0.1)$ $>\mathrm{Mo}(0.01)>\mathrm{Ta}(0.006)>\mathrm{W}(0.004)$. In this enumeration, the numbers in parenthesis represent the relative ratios to the generation rate of iron metal, which is counted 1.0. The related data were obtained at the same input power and experimental conditions of $50 \% \mathrm{H}_{2}-50 \%$ Ar atmosphere [22]. From above experimental results and thermodynamic calculations on evaporation rates of each metal, they concluded that the driving force for the generation of particles from metals is much concerned with physical properties of metal, such as, heat of vaporization and melting points of metals. For the improvement of these generation rates, the injection of reducing gas, such as, $\mathrm{N}_{2}$ and $\mathrm{H}_{2}$, can be helpful regardless of their melting points [22-24]. In addition, it is also worth noticing that some patented apparatus uses the spherical target materials as anodes for their easy evaporation [24-26]. By adopting spherical shape anode targets, it has been explained that formation of melted slags can be minimized and hydrogen permeation into target materials is also expedited.

Since the anode electrodes are made of consumable target materials in these applications, however, they should be replenished after each batch of metal nano-powders, and consequently, the production process using transferred DC plasma torch becomes often non-continuous. As an alternative to this batch process, non-transferred DC or RF plasma torches have been equipped in continuous production system of nano-sized powders. Fig. 2 (b) shows a typical usage of non-transferred DC plasma torches for continuous production of metal powders. In this figure, the targeted materials are injected into thermal plasma flame as a precursor powder while the torch electrodes are used only for maintaining the formation of arc plasma [27-28]. For effective heating of the precursors, injection ports can be located on the inner surface of cylindrical anode nozzle [29]. With the injection ports at torch exit, which is conventionally used for plasma spray coating applications, however, it is hard for this type of DC torch to enable most of the injected precursors to be fully evaporated during their flight of plasma flame. As reported in other papers [30-32], there are many trajectories far from full evaporation of injected metal precursors in this case. Although smaller particles are relatively easily evaporated, some parts of the precursors injected into the plasma flame can be still reproduced without full evaporation due to their ineffective trajectories [33].

As a heat source to alleviate incomplete heating problems of injected precursors, RF plasma torches have

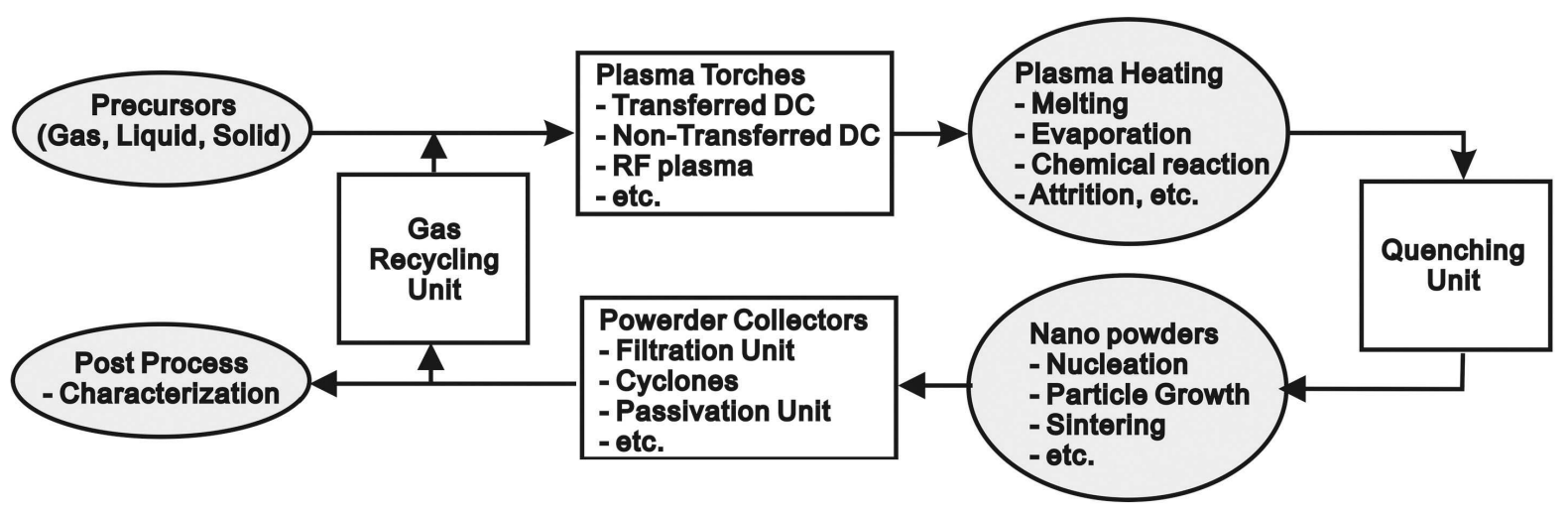

Fig. 1. Thermal Plasma Synthesis Procedure for the Production of Nano-sized Powders. 
attracted much attention. Since this type of torch needs no electrode for sustaining plasma, axial injection of precursor along the centerline of RF torch is possible as illustrated in Fig. 2 (c). Accordingly, high temperature region of RF plasma can be effectively used in heating up the solid precursors if they are injected along the centerline of the torch. The absence of an electrode is also advantageous for the synthesis of high purity materials. Thanks to these advantages in in-flight treatment of injected solid precursors, RF plasma torches have been widely adopted to make a variety of small sized metal powders [34-40]. For example, $\mathrm{Al}, \mathrm{Ni}$, and $\mathrm{W}$ metals with micron-sizes can be reformed into small particles with average diameters around $50 \mathrm{~nm}$ at the plate power level of 60 70 kW and the feed rate of 19 20 g/min [34]. Compared with a non-transferred DC plasma torch, however, the competitive advantages of a RF plasma torch come from not only its high enthalpy available along the centerline of the RF plasma torch but also relatively long residence time of axially injected precursors. From the numerical simulations using metal or ceramic particles with sizes of $20 \sim 60 \mu \mathrm{m}$, such as, $\mathrm{Fe}, \mathrm{Ni}, \mathrm{Cu}, \mathrm{W}$ and $\mathrm{Al}_{2} \mathrm{O}_{3}$, their complete evaporation has been expected to take times of $4.5 \sim 8.5 \mathrm{~ms}$ along the centerline of the RF plasma torch [35-37]. In other words, if the solid precursors are injected at the velocity of $20 \mathrm{~m} / \mathrm{sec}$, evaporation times of $4.5 \sim 8.5 \mathrm{~ms}$ require torch lengths of $100 \sim 170 \mathrm{~mm}$. Since these lengths are easily attainable by an RF plasma torch combined with an extended cylindrical reactor [38], many kinds of metal and oxides with micron sizes are expected to be immediately heated up to their evaporation points by the RF plasma torch system. The extended cylindrical reactor can be designed to expand and decelerate the RF plasma flame by enlarging its diameter compared with RF torch diameter as shown in Fig. 3 [41]. In the designed system of Fig. 3, the RF plasma torch plays a role of heat source for melting or evaporation of the precursors injected along the centerline of the torch. Moving axially along the centerline, however, some of the heated precursors can spread out radially due to the convection and diffusion processes existing in plasma flow. After issuing out the exit of RF plasma torch, these radially dispersed trajectories can escape the hot region of plasma flame, which flows axially along the centerline of reactor. As a result, the precursors escaping from this hot region

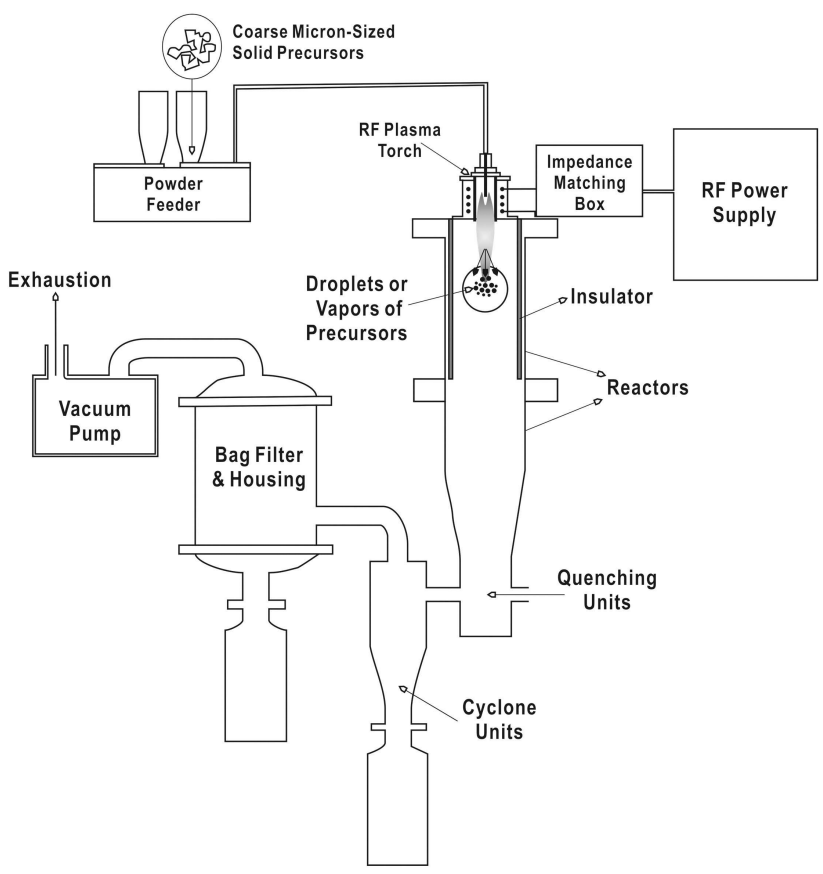

Fig. 3. A Schematic of an RF Plasma Torch System Designed for Synthesis of Nano-sized Powders [41].

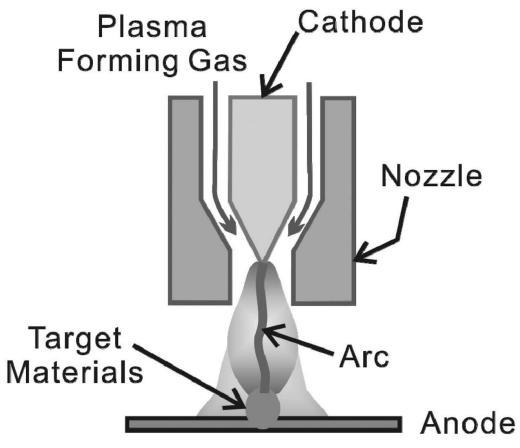

(a)

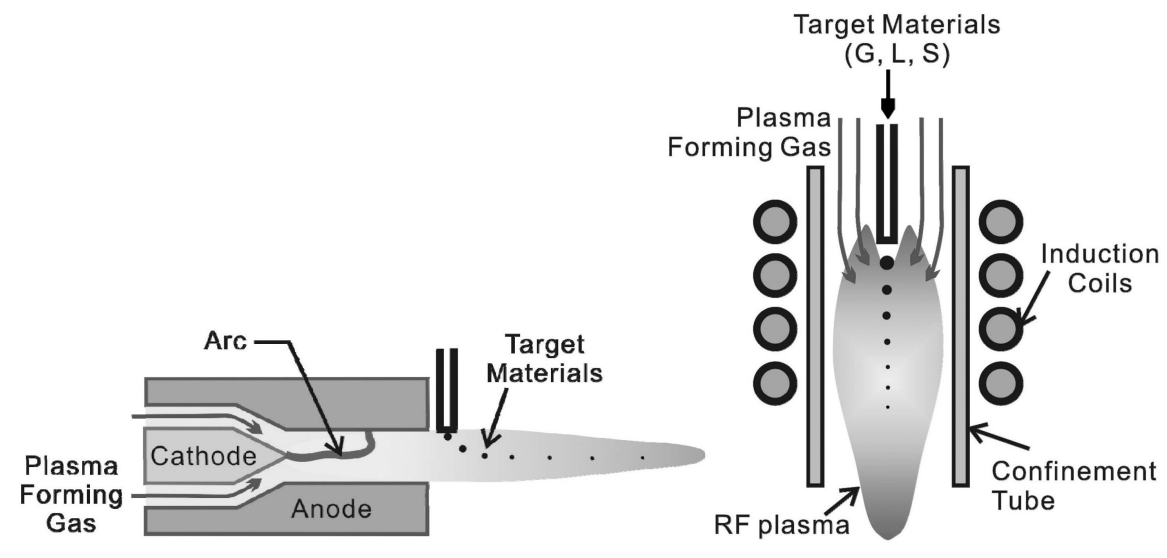

(b) (c)

Fig. 2. Schematic Diagrams of the Typical Thermal Plasma Torches Available for Synthesis of Nano-sized Powders. ((a) Transferred DC Plasma Torch, (b) Non-transferred DC Plasma Torch and (c) RF Plasma Torch) 
of plasma flame may be cooled down rather than heated up. Consequently, radial expansion of RF plasma flame in a reactor may provide these precursors with extended residence time in hot region of plasma flame. In order to estimate these effects, a lot of modeling and experimental works have been conducted for the RF plasma torches coupled with reactors coaxially [42-46]. From these works, it has been confirmed that high temperature region can be expanded radially with the deceleration of RF plasma flows in a reactor having a diameter larger than one of RF plasma torch. However, the extent of the high temperature region, e.g., isothermal lines corresponding to critical temperatures, such as, 3,000 $\mathrm{K}$ for the boiling point of $\mathrm{Ni}$, is not so large compared with the diameters of RF plasma torches. For example, expanded diameters of 3,000 $\mathrm{K}$ isothermal lines range from $60 \sim 70 \mathrm{~mm}$ for the RF plasma torches with a diameter of $\sim 50 \mathrm{~mm}$ [42-46]. Accordingly, a cylindrical reactor with a slightly enlarged diameter can be helpful for effective use of RF plasma enthalpy by concentrating the expanded high temperature region. Apart from reactor design, however, heating process of injected metal precursors is significantly dependent on various operation parameters, such as, plasma input power, feeding rate, and precursor sizes. For example, Ni particles with sizes of $60 \mu \mathrm{m}$ have been calculated to remain mostly unevaporated at torch exit when their feeding rate is increased over $30 \mathrm{~g} / \mathrm{min}$ with a RF input power of $5 \mathrm{~kW}$ [37]. Whereas, small sizes of the injected precursors are normally in favor of complete evaporation with the increase of RF input power. In other words, high powered RF plasma torch system may be preferred for mass treatment of small sized precursors. Recently, RF plasma torch systems with plate power level of $200 \sim 300 \mathrm{~kW}$ have been commercialized together with high performance feeder for micron-sized powders [38].

Finally, it should be noted that prepared metal powders with very small sizes should be passivated for safety before their exposure to atmosphere.

\section{THERMAL PLASMA SYNTHESIS OF NANO- SIZED NON-METAL POWDERS}

Similar to the synthesis of nano-sized metal powders, size reducing of a solid precursor by thermal plasma may be the simplest way to obtain nano-sized non-metal powders. Some kinds of materials can be successfully reformed into nano-sized powders in this way. As a typical example, Fig. 4 shows the transformation of micronsized glass powders into nano-sized ones. In this figure, one can see that the sizes of glass precursors are reduced down to $<500 \mathrm{~nm}$ after their in-flight treatment using RF thermal plasma $[41,47]$. In this special case, RF plasma torch was used as a powerful heat source to evaporate the micron-sized glass frits for their re-synthesis into very small particles. With the same purposes, other kinds of single phase oxides, such as, $\mathrm{ZrO}_{2}, \mathrm{SiO}_{2}, \mathrm{Al}_{2} \mathrm{O}_{3}$ and $\mathrm{TiO}_{2}$, have been tested by various types of plasma torches [4852]. In these applications, however, changes of their crystalline structures have been observed with successful size reduction, such as, amorphization of $\mathrm{SiO}_{2}$ and phase transition in $\mathrm{TiO}_{2}$. For some specialty nano-powders, however, these changes in crystalline structures can be enhanced intentionally by modification of plasma torch system. For example, B. Bora et.al.'s have used a supersonic DC plasma torch for achieving specialty $\mathrm{Al}_{2} \mathrm{O}_{3}$ nano-powders with amorphous crystalline structures [53]. In their experiment, a supersonic Laval nozzle was attached to a non-transferred DC plasma torch in order to obtain high quenching rate requested for amorphization of the in-flight treated $\mathrm{Al}_{2} \mathrm{O}_{3}$ precursors [53-55].

These size reducing processes of refractory non-metal solid precursors, however, often show a limitation for large scale application because the dense loading effect on the evaporation of injected materials becomes severe as feeding rate is increased for mass production [37]. Actually, it has been estimated by M. Kambara et. al.'s
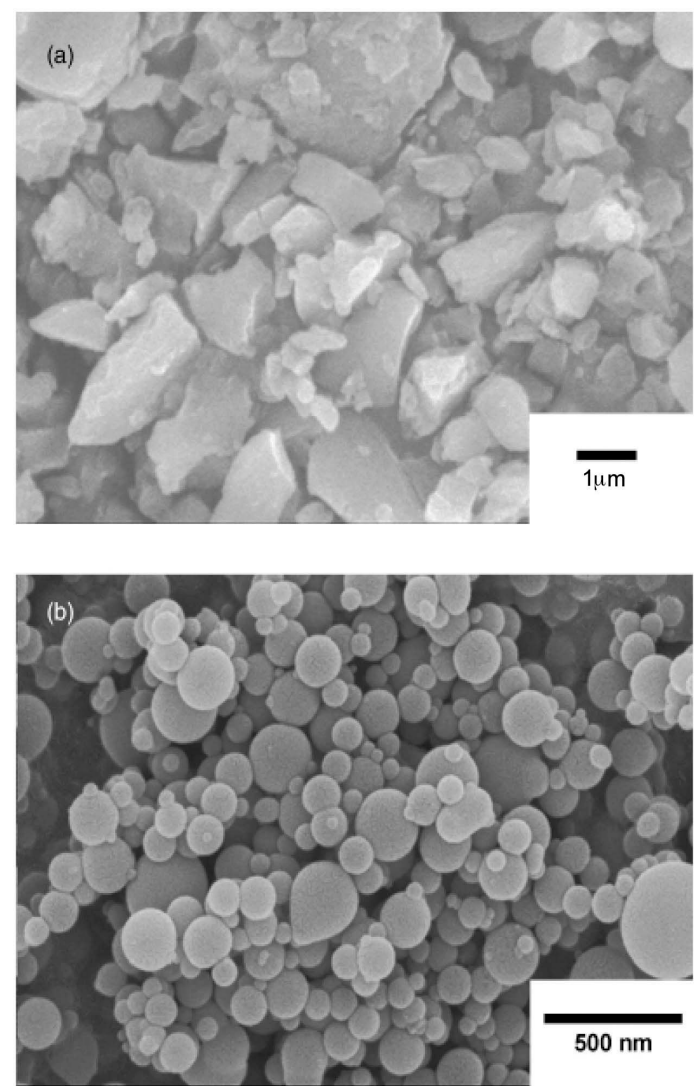

Fig. 4. Comparison of FE-SEM Images Between (a) the Micrometer-sized Coarse Glass Powders before the RF Plasma Treatment and (b) the as-treated Nano-sized Ones [41]. 
[56] that solid fine powders can be evaporated at $1 \mathrm{~kg} / \mathrm{h}$ by a $100 \mathrm{~kW}$ class RF plasma system. At the same power level, however, they insisted that liquid and gaseous precursors can be treated at 10 and $100 \mathrm{~kg} / \mathrm{h}$, respectively. Accordingly, the choice of precursors needs to be determined in the basis of economical worth. For example, some kinds of nano-materials are obtainable in a large scale by means of direct decomposition of liquids or gaseous precursors using thermal plasmas. Carbonaceous nano-materials, such as CNT (carbon nanotubes) and specialty CB (carbon black), may be the most notable examples. Traditionally, CNTs with high purity have been obtained using the transferred DC arc discharge generated by graphite electrodes [57-60]. Due to the limitations of the batch process inherent in this type of plasma system, however, there have been many efforts to produce CNTs continuously by decomposing liquid or gas phase hydrocarbons with non-transferred DC or RF plasma torches [61-64]. For example, Choi et. al. reported that continuous production of CNTs can be processed by injecting $\mathrm{CH}_{4}$ gas and Ni-Y catalyst into the flame of non-transferred DC plasma torch [61]. In this experiment, multi-walled CNTs are mainly produced with high purity as shown in Fig. 5 at very high growth rate. Besides CNTs, the high enthalpy of thermal plasma has also been employed as a main heat source to decompose hydrocarbons into hydrogen rich fuels and solid carbon black, so called, plasma black [6570]. As reported in many other papers and patents [65-70], plasma black can be formed like crinkled papers having well-developed graphite crystallites since they are produced at high temperatures over $2,000 \mathrm{~K}$ by thermal plasmas. Fig. 6 shows an example of this specialty plasma black, which was obtained from methane decomposition by a non-transferred DC plasma torch [70].

In the applications above mentioned, thermal plasmas are mainly used as a heat source for evaporation of solid precursors or decomposition of gaseous precursors. In other words, plasma forming gases will take little part in the synthesis process of nano-sized particles except the role of heat transfer media. If the reactive gases, such as, oxygen and nitrogen, are used as one of the main constituents to form a plasma flame, however, chemical reactions between the radical reactive species and the heated precursors can be conducive to synthesis of nano-sized materials. Many kinds of oxides, carbides and nitrides have been synthesized in this way [10,71-74]. For example, nano-sized $\mathrm{Al}_{2} \mathrm{O}_{3}$ or $\mathrm{TiO}_{2}$ particles can be easily obtained by in-flight treatment of Al metal or titanium hydrides in oxidative thermal plasma [71,72]. Since the oxidation reaction of metal is normally exothermic, these processes can be more energy

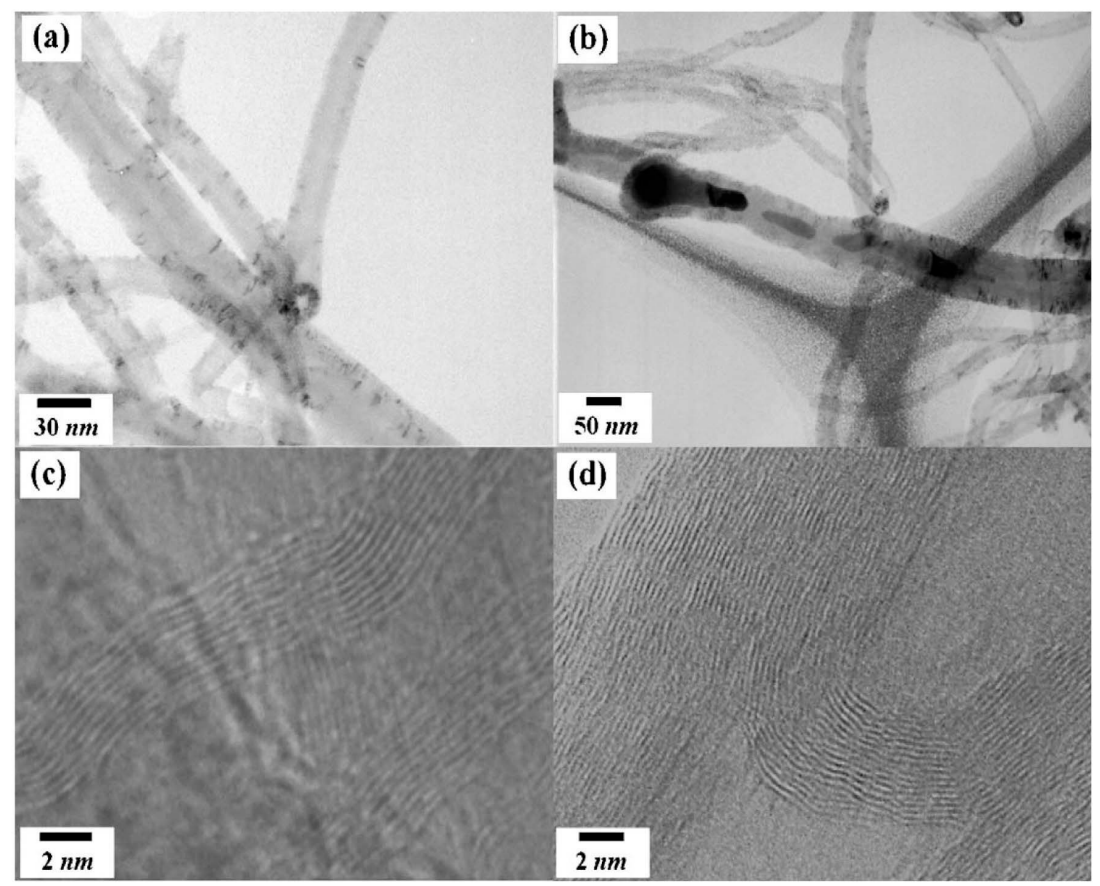

Fig. 5. High-resolution TEM Images of CNTs Prepared by Non-transferred DC Plasma Torch: (a) Open-tip CNTs, (b) Encapsulated Tip and Partially Filled CNTs, (c) wall Structure of a Cylindrical Multi-walled CNT, and (d) wall Structure of a Bamboo-like Multi-walled CNT [61]. 


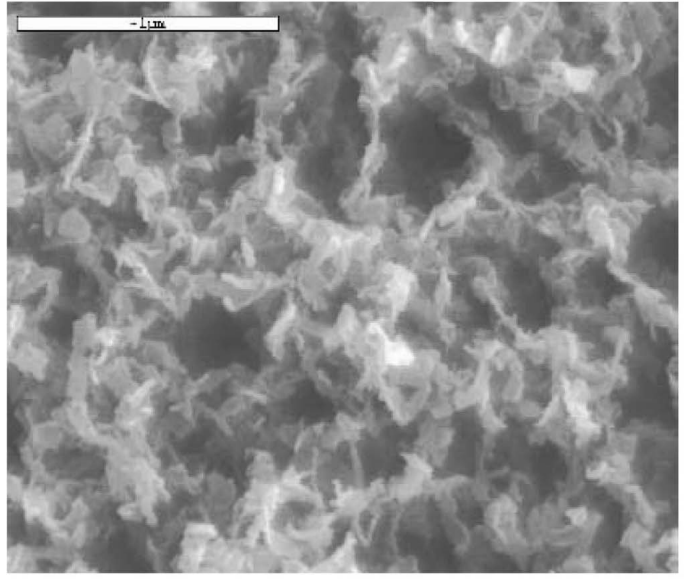

(a)

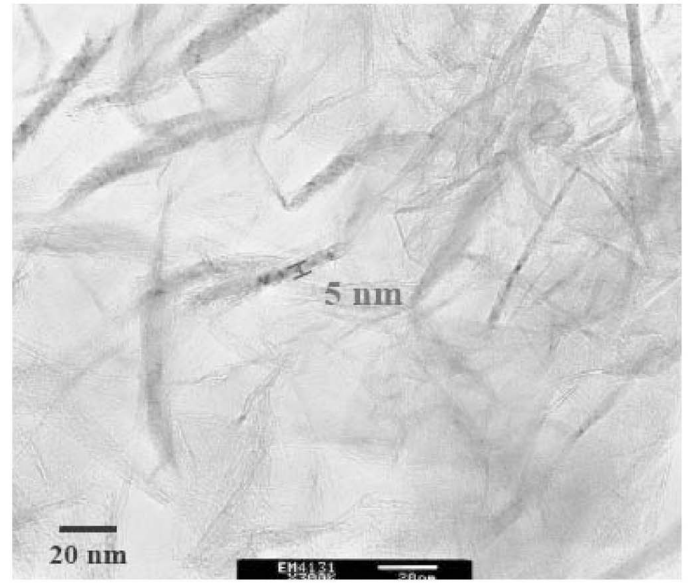

(b)

Fig. 6. FE-SEM (a) and TEM (b) Images of Carbon Black Obtained from $\mathrm{CH}_{4}$ Gas Decomposition by Non-transferred DC Plasma Torch.

effective compared with size reduction of micron-sized $\mathrm{Al}_{2} \mathrm{O}_{3}$ or $\mathrm{TiO}_{2}$ precursors into nano-sized particles. In addition to these nano-sized oxide powders, a variety of carbides with submicron sizes, such as, nano-sized SiC, $\mathrm{WC}$ and $\mathrm{TiC}$, have been prepared using reactive thermal plasmas [73-77]. In these applications, liquid or gaseous hydrocarbons, such as methane, can be adopted as a cheap and commercially useful carbon source [73-74, 77]. As for the cation sources for those covalent and metallic carbides, metal powder itself or chemicals containing each metal cation can be used, depending on the thermodynamics of targeted materials and the types of plasma torches. In a similar way, nano-sized nitride powders have been synthesized by nitrogen thermal plasma [76,78-79]. For example, ultrafine AlN powders can be synthesized from in-flight treatment of $\mathrm{Al}$ powder by thermal plasma containing $\mathrm{N}_{2}$ gas [78-79]. Moreover, $\mathrm{Si}_{3} \mathrm{~N}_{4}$ nano powders have been reported to be prepared by the RF thermal plasma with $\mathrm{N}_{2}$ content more than $60 \mathrm{vol} \%$ of the plasma forming gas [76].

\section{THERMAL PLASMA SYNTHESIS OF SPECIALTY NANO-COMPOSITE POWDERS}

In spite of various attempts mentioned above, reactive thermal plasma is limited to only a few kinds of nano-sized powders because of the difficulty in achieving reproducible processes [10]. Additionally, the composition of the plasma forming gas should be optimized experimentally to each application in order to match the stoichiometry of synthesized ceramics, such as, oxides, carbides and nitrides [76]. For these reasons, in-flight treatment of solid precursors may be preferred in some practical applications due to their reproducibility as well as simplicity of the plasma material process although the treatment capacity is often short of the industrial requirements. Among them, supported metal catalysts and core-shell structured nano-powders may be promising. For example, solid solution $\mathrm{NiO}-\mathrm{MgO}$ catalysts with very small sizes have attracted much attention in $\mathrm{CO}_{2}$ reforming of methane because of their high activity and selectivity as well as excellent stability during this reforming process [80]. Since the high performance of these catalysts comes from the structural features of $\mathrm{NiO}-\mathrm{MgO}$ solid solution as well as the increased $\mathrm{Ni}$ metal surface, many efforts have been focused on finding the preparation methods to enhance the degree of solid solution at the increased content of Ni metals [80-83]. As a new route for this purpose, we introduced in-flight thermal plasma treatment of mixture precursors consisting of $\mathrm{Ni}$ metal and $\mathrm{MgO}$ oxide particles [84]. In our experiment using a RF plasma torch, it was found that mixture of $\mathrm{Ni}$ metal $(\sim 5 \mu \mathrm{m})$ and $\mathrm{MgO}$ oxides $(\sim 200 \mathrm{~nm})$ can be reformed into nano-sized $\mathrm{Ni}$ particles $(<100 \mathrm{~nm})$ attached to $\mathrm{MgO}$ nano-rods with diameters of 10-20 nm as shown in Fig.7. In these reformed composites, the formation of a solid solution between $\mathrm{Ni}$ particles and $\mathrm{MgO}$ nano-rods was confirmed from the XRD data. Thanks to these structural properties of as-prepared composites as well as the reduced sizes of the Ni metal, as-synthesized $\mathrm{NiO}-\mathrm{MgO}$ nano-powders showed not only high catalytic activity but also negligible carbon coking during the partial oxidation reaction of methane at $750{ }^{\circ} \mathrm{C}$ for $24 \mathrm{hr}$. As reported in other papers, high catalytic activity can be attributed to the small sized Ni metal particles, which are dispersed on the $\mathrm{MgO}$ nano-rods in Fig. 7. On the other 


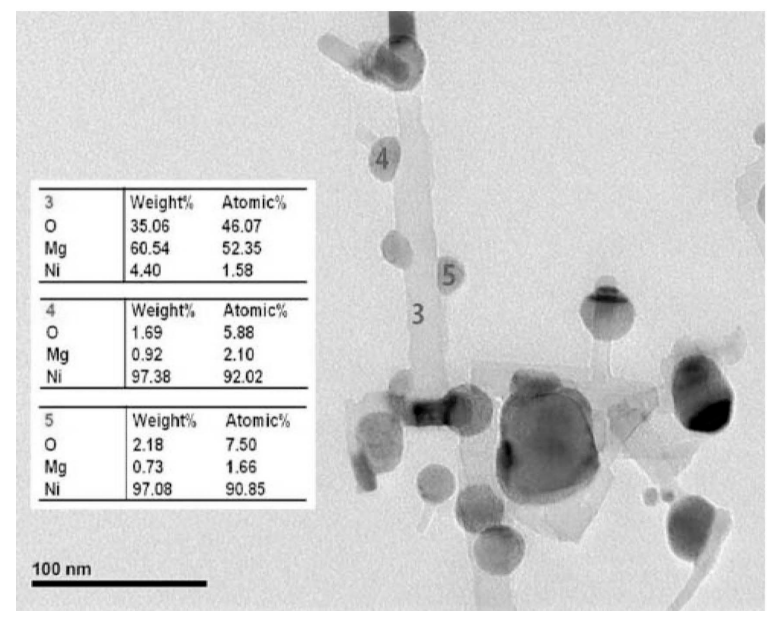

Fig. 7. TEM Image for As-prepared NiO-MgO Solid Solution Composite. The Inset Represents the Results of EDS Analysis [84].

hand, the enhanced resistance to carbon coking seems to be caused by the structural advantages originating from the formation of a $\mathrm{NiO}-\mathrm{MgO}$ solid solution. From these experimental results, we expect that simultaneous treatment of $\mathrm{Ni}$ metal and $\mathrm{MgO}$ oxides can meet two requirements of oxide supported $\mathrm{Ni}$ catalysts (i.e., very small $\mathrm{Ni}$ metal particles and the formation of $\mathrm{NiO}-\mathrm{MgO}$ solid solution). In this case, it is believed that $\mathrm{Ni}$ metals $(\sim 5 \mu \mathrm{m})$ injected with $\mathrm{MgO}$ powders may experience the preferential evaporation during their RF plasma heating. For $\mathrm{MgO}$ precursors, however, the heat transfer from the RF plasma seems to be just enough for their changes of shape into nano-rods. As a result, $\mathrm{MgO}$ nano-rods can work as a nucleation seed for $\mathrm{Ni}$ vapors during the quenching process, which leads to very small Ni particles dispersed on the surface of $\mathrm{MgO}$ nano-rods as shown in Fig. 7. In addition, the consecutive consolidation process starts at the temperatures near the melting points of each element, and accordingly, the formation of $\mathrm{NiO}-\mathrm{MgO}$ solid solution can also be expected on the interfaces between $\mathrm{MgO}$ nanorods and Ni droplets at those temperatures [84]. Instead of refractory oxide support, such as $\mathrm{MgO}, \mathrm{H}$. Zea et. al [85] have prepared carbon supported metal catalysts using a non-transferred DC plasma torch. Unlike MgO support, however, the in-flight heating of carbon injected with $\mathrm{Pd}$ metal resulted in the loss of carbon surface area due to the removal of all oxygen groups from carbon supports by plasma treatment. In addition, they also reported that mixture precursors consisting of $\mathrm{PdAg}$ metal and $\mathrm{Al}_{2} \mathrm{O}_{3}$ oxides leads to significant metal loss in as-prepared catalysts because of the burial of metal particles into $\mathrm{Al}_{2} \mathrm{O}_{3}$ pores during their plasma treatment [85-86]. Compared with the melting points of $\mathrm{MgO}\left(2,852^{\circ} \mathrm{C}\right)$ and $\mathrm{Al}_{2} \mathrm{O}_{3}$ $\left(2,072{ }^{\circ} \mathrm{C}\right)$, these results indicate that oxide supports with

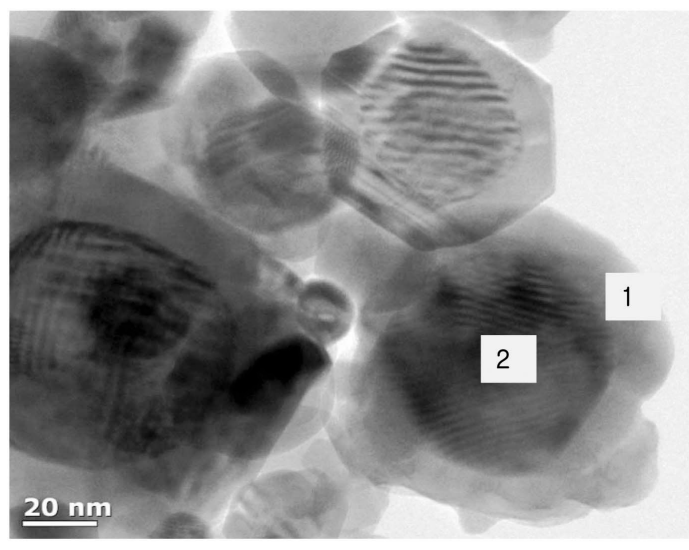

\begin{tabular}{c|cccc}
\hline $\begin{array}{c}\text { Spectrum } \\
\text { (at\%) }\end{array}$ & $\mathbf{0}$ & $\mathrm{Ti}$ & $\mathrm{Ni}$ & $\mathrm{Ba}$ \\
$\mathbf{1}$ & $\mathbf{3 0 . 1 9}$ & 28.01 & 5.69 & 36.12 \\
2 & 20.50 & 6.03 & 67.75 & 5.72 \\
\hline
\end{tabular}

Fig. 8. TEM Image of Ni Core - $\mathrm{BaTiO}_{3}$ Shell Structured Nano-particles Synthesized by RF Plasma Treatment of Mixture Precursors Consisting of Ni Metal and $\mathrm{BaTiO}_{3}$.

high melting points are favorable in the thermal plasma synthesis of supported metal catalysts without metal loss.

This burial phenomenon of metal particle into ceramic pores with relatively low melting points can be, however, very useful in making a unique nano-material with coreshell structures. As disclosed in K. Nishmura et.al.'s patent [87], mixture precursors of $\mathrm{Ni}$ metal and $\mathrm{BaTiO}_{3}$ can be easily reformed into $\mathrm{Ni}$ core $-\mathrm{BaTiO}_{3}$ shell structure by the RF thermal plasma. In this case, Ni metal burial into $\mathrm{BaTiO}_{3}$ oxide can take a place as discussed previously since $\mathrm{BaTiO}_{3}$ has a relatively low melting point of $1,625^{\circ} \mathrm{C}$. Fig. 8 shows the TEM image of these Ni core $-\mathrm{BaTiO}_{3}$ shell structures, which is reproduced similarly to the approach in K. Nishmura et al.'s patent [87] using RF plasma torch system. In the same fashion, inorganic materials with low melting points, such as, glass, can also be used as the shell of a metal core [88]. These core-shell structured materials may be promising as the advanced nano-materials in MLCC or secondary battery. From the above results, it can be concluded that mixture precursors consisting of metal and ceramic materials can be reformed into nano-sized powders with a metal core - ceramic shell structure depending on the melting points of the shell materials. For the refractory ceramics with relatively high melting points, however, metal vapors tend to be nucleated on their surfaces, and then, to experience some kinds of high temperature reactions with heated ceramic surface, such as solid solution, sintering and other kinds of high temperature chemical reactions. 
As a different example of the core-shell structured materials, it may be notable that transferred arc discharge on the mixtures of carbonaceous materials and metal powders can produce nano metal particles encapsulated by a carbon cage [89-91]. For example, Fe metal particles can be easily encapsulated by carbon layers as shown in Fig. 9 [90]. However, Si metal has been failed to fill the

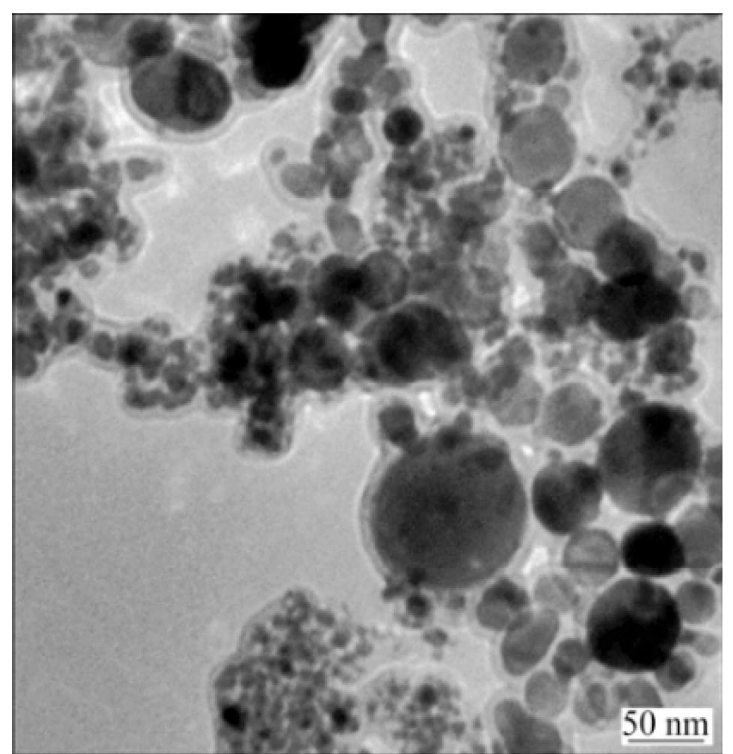

Fig. 9. TEM Image of Carbon Encapsulated Fe Nanoparticles [90]. hollow carbon cages due to its strong tendency of carbide formation [91]. In these processes, the formation of carbon nanocapsules filled with Fe particles is attributed to the precipitation of carbon species solved in Fe metal droplets during their co-condensation [89]. If the carbide formation is preferred during the co-condensation, however, it is hard for the impregnated carbon species to escape from the metal lattices without carbon-metal reaction. It is interesting to compare this carbon caged metal particles with metal core - ceramic shell structures. In the case of metal core ceramic shell structures, ceramic or glass materials with relatively low melting points absorb the metal particles, firstly, and then, their increased viscosity seems to play a role of cage to inhibit the emission of metal particles during quenching process. Different from ceramic or glass materials, carbon has no liquid state but its boiling point is very high over than $3,000{ }^{\circ} \mathrm{C}$. Accordingly, it is more natural for the solid carbon to be impregnated into metal droplets, and then, precipitated in the form of carbon cage during their co-condensation processes.

Besides metal-ceramic or metal-carbonaceous materials, ceramic-ceramic nano composites can also be made by in-flight treatment of their mixture precursors. Fig. 10 shows ternary IZTO (indium zinc tin oxide) nano powders synthesized by RF thermal plasmas [92]. In this case, three kinds of oxides, such as, $\mathrm{In}_{2} \mathrm{O}_{3}, \mathrm{ZnO}$ and $\mathrm{SnO}_{2}$, are injected into a RF plasma flame with the preset cation ratios of $6: 2: 2$. From this in-flight treatment, IZTO powders with a single phase of $\operatorname{In}_{2} \mathrm{O}_{3}$ structure can be achieved [92]. Since those three oxides have the relatively low melting points of $<2,000{ }^{\circ} \mathrm{C}$, their surface can be heated up to
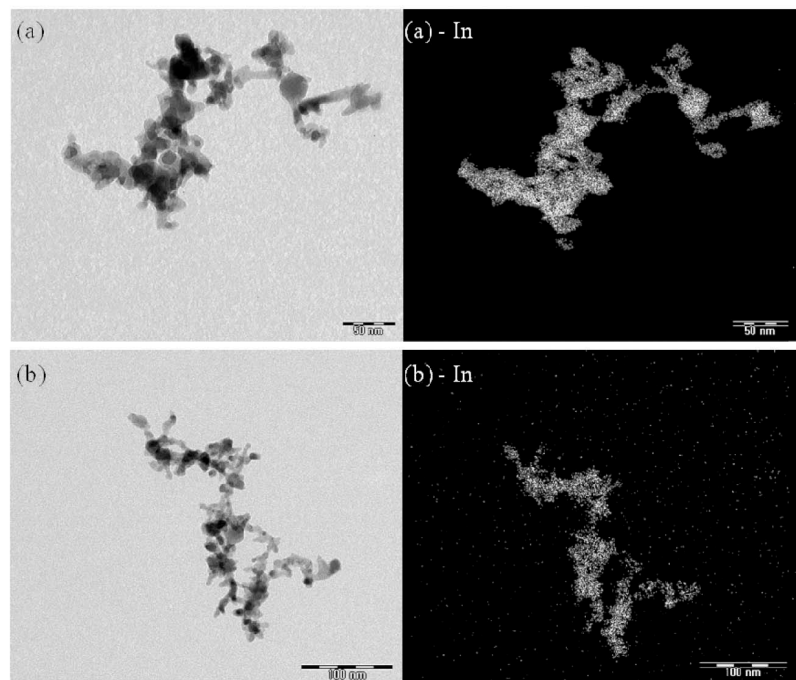

(a) $-\mathrm{Zn}$

(a) $-\mathrm{Sn}$
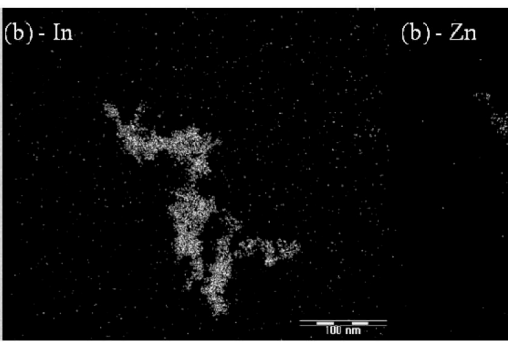

(b) $-\mathrm{Zn}$
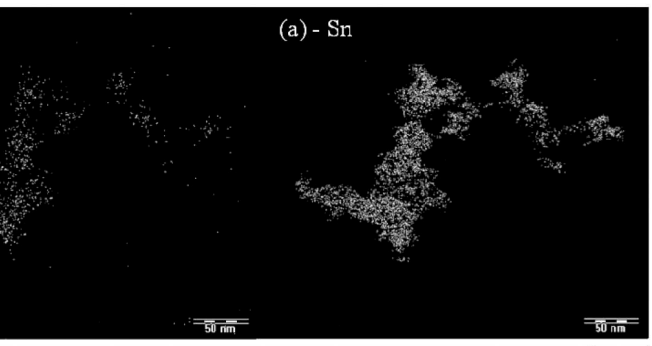

Fig. 10. Comparison of TEM-EELS Mapping Images between the As-synthesized IZTO Powders ((a), (b)), which have Molecular Ratios of $\mathrm{In}_{2} \mathrm{O}_{3}: \mathrm{ZnO}: \mathrm{SnO}_{2}$ at 3:2:2 and 1:1:1, Respectively. The Terms of In, $\mathrm{Zn}$ and Sn in Each Mapping Image Represent Indium, Zinc and Tin Elements Distributed in the As-synthesized Particles [91]. 
high temperatures enough for solid solution and sintering reactions between each oxide. In this experiment, $\operatorname{In}_{2} \mathrm{O}_{3}$ takes a $60 \mathrm{ca} . \%$ of precursors, and consequently, these solid solution and sintering reactions may be based on $\mathrm{In}_{2} \mathrm{O}_{3}$, such as the incorporation of $\mathrm{ZnO}$ and $\mathrm{SnO}_{2}$ into $\mathrm{In}_{2} \mathrm{O}_{3}$ structure, which leads to a unified IZTO powders with a single phase of $\operatorname{In}_{2} \mathrm{O}_{3}$ structure. However, thermal plasma synthesis of ternary nano-powders is still unreliable in stoichiometry, and accordingly, more research is needed to clarify the thermal plasma synthesis mechanism of ternary and higher nano-materials.

\section{CONCLUSION}

In recent decades, nano-sized materials have been widely synthesized using thermal plasma torches. Depending on the features of the target materials and employed plasma torches, various synthesis routes have been presented. For example, a single phase metal particle with sizes around $50 \mathrm{~nm}$ can be produced directly from bulk metal using transferred DC arc plasma. For the same purpose, nontransferred DC or RF plasma torches have also been adopted. In these cases, however, nano-sized metal particles are normally obtained by in-flight treatment of solid metal precursors with sizes of under several tens micro-meter.

In-flight treatment of solid precursors may be preferrable in the preparation of nano-sized glass powders and single phase oxides, such as, $\mathrm{ZrO}_{2}, \mathrm{SiO}_{2}, \mathrm{Al}_{2} \mathrm{O}_{3}$ and $\mathrm{TiO}_{2}$. Among them, single phase oxides can be prepared by reactive thermal plasmas synthesis. However, their reproducibility and stoichiometry problems should be solved for practical applications. In spite of this limitation, reactive thermal plasmas are still important in the synthesis of nitrides and carbides with very small sizes. For specialty nano-powders, such as, oxide supported catalysts and core-shell structured nano materials, in-flight treatment of metal-ceramic mixture precursors can be applied. Depending on the physical properties of ceramic materials, such as melting points, the treated products can become a metal core - ceramic shell structured particle or a metal catalyst dispersed on ceramic supports. For the ceramic powder of $\mathrm{BaTiO}_{3}$ with relatively low melting point, the mixed $\mathrm{Ni}$ metals can be buried into $\mathrm{BaTiO}_{3}$ droplets and reformed into $\mathrm{Ni}$ core - $\mathrm{BaTiO}_{3}$ shell structured nano-composite. Similar results can be obtained in the form of $\mathrm{Ni}$ core - glass shell structures. For the refractory $\mathrm{MgO}$ particles, however, they seem to experience the change of shape into nano-rods instead of evaporation, and then, support highly dispersed $\mathrm{Ni}$ particles with the formation of $\mathrm{NiO}-\mathrm{MgO}$ solid solution.

Carbonaceous materials, such as CNTs, carbon black and nano metal particles encapsulated in a carbon cage, can also be produced by transferred DC arc discharge as well as other types of torches. However, it should be noted that the properties of produced carbonaceous materials depend on the used plasma torch systems. Based on these review results, it can be concluded that the advantages of thermal plasmas, such as, high enthalpy flows combined with a rapid quenching rate, can be very promising in the synthesis of not only a single phase material but also binary or higher nano-materials.

\section{REFERENCES}

[ 1] M. I. Boulos, P. Fauchais and E. Pfender, Thermal Plasmas : Fundamentals and Applications, Volume 1, Plenum Press, New York and London, 1994.

[2] P. Fauchais and A. Vardelle, "Thermal plasmas," IEEE Trans. Plasma Sci., 25, 1258 (1997).

[3] Y. P. Raizer, Gas Discharge Physics, Springer-Verlag, Berlin Heidelberg, 1991.

[4] E. Pfender, "Thermal Plasma Technology: Where Do We Stand and Where Are We Going?," Plasma Chem. Plasma Process., 19(1), 1 (1999)

[ 5 ] M. I. Boulos, "The inductively coupled R.F. (radio frequency) plasma," Pure \& Appl. Chem. 57, 1321 (1985).

[6] J. Heberlein, "New approaches in thermal plasma technology," Pure \& Appl. Chem., 74(3), 327 (2002).

[ 7 ] B. Pateyron, M. F. Elchinger, G. Delluc and P. Fauchais, "Sound Velocity in Different Reacting Thermal Plasma Systems," Plasma Chem. Plasma Process., 16(1), 39 (1996).

[ 8 ] T. Yoshida, "The future of thermal plasma processing," Mater. T. JIM, 31(1), 1 (1990)

[9] P. R. Taylor and S. A. Pirzada, "Thermal Plasma Processing of Materials: A Review," Adv. Perform. Mater., 1, 35 (1994).

[10] P. Fauchais, A. Vardelle and A. Denoirjean, "Reactive thermal plasmas: ultrafine particle synthesis and coating deposition," Surf. Coat. Tech. 97, 66 (1997).

[11] D. Vollath, "Plasma synthesis of nanopowders," $J$. Nanopart. Res., 10, 39 (2008).

[12] J. R. Fincke, W. D. Swank, S. C. Snyder and D. C. Haggard, "Enthalpy probe performance in compressible thermal plasma jets", Rev. Sci. Instrum., 64(12), 3585 (1993).

[13] M. Rahmane, G. Soucy and M. I. Boulos, "Analysis of the enthalpy probe technique for thermal plasma diagnostics", Rev. Sci. Instrum., 66(6), 3424 (1995).

[14] S. Choi, T. H. Hwang, J. H. Seo, D. U. Kim and S. H. Hong, "Effects of Anode Nozzle Geometry on Ambient Air Entrainment Into Thermal Plasma Jets Generated by Nontransferred Plasma Torch," IEEE Trans. Plasma Sci., 32(2) (2004).

[15] J. H. Park and S. H. Hong, "Optimization analysis of an inductively coupled torch for material processing by using local thermal equilibrium numerical analysis," J. Kor. Phys. Soc., 31, 753 (1997).

[16] M. Rahmane, G. Soucy and M. I. Boulos, "Diffusion phenomena of a cold gas in thermal plasma stream," $J$. Plasma Chem. Plasma Proces., 16, 169S (1996).

[17] R. Ye, P. Proulx and M. I. Boulos, "Turbulence phenomena in the radio frequency induction plasma torch," Int. J. Heat Mass Trans., 42, 1585 (1999).

[18] Ph. Buffat and J. P. Borel, "Size effect on the melting temperature of gold partlcles," Phys. Rev. A, 13, 2287 (1976)

[19] Ed. by C. Corti and R. Holliday, Gold : science and applications, CRC Press Taylor \& Francis Group, NewYork, 2010. 
[20] Ed. by D. L. Feldheim and C.A. Foss. Jr., Metal Nanoparticles : Synthesis, Characterization, and Applications, Marcel Dekker Inc., New York, Basel, 2010.

[21] Y. L. Lee, J. W. Joung and K. J. Lee, Method for manufacturing nickel nanoparticles, US Patent 7648556 B2.

[22] S. Ohno and M. Uda, "Generation rate of ultrafine metal particles in hydrogen plasma - metal reaction," J, Jpn. Insl. Met., 48, 640 (1984). (Japanese)

[23] A. M. Fudoligh, H. Nogami and J. Yagi, "Prediction of generation rates in 'reactive arc plasma' ultrafine powder production process, ISIJ Int., 37, 641 (1997)

[24] M. Uda, S. Ohno and T. Hoshi, Process for production fine metal particles, US Patent 4376740.

[25] M. Uda, S. Ohno and H. Okuyama, Process for production particles of ceramic, US Patent 4889665.

[26] T. Araya, Y. Ibaraki, Y. Endo, S. Hioki and M. Kanamaru, Arc apparatus for producing ultrafine particles, US Patent 4732369.

[27] M. Shigeta and A. B. Murphy, "Thermal plasmas for nanofabrication," J. Phys. D: Appl. Phys., 44, 174025 (2011)

[28] S. H. Lee, S. M. Oh and D. W. Park, "Preparation of silver nanopowder by thermal plasma," Mater. Sci. Eng. C, 27, 1286 (2007)

[29] M. Ogawa and S. Abe, Method for making ultra-fine ceramic particles, US Patent 4610857.

[30] S. Kumara, V. Selvarajan, P.V.A. Padmanabhan and K.P. Sreekumar, "Spheroidization of metal and ceramic powders in thermal plasma jet: Comparison between experimental results and theoretical estimation," J. Mater. Process. Tech., 176, 87 (2006)

[31] H. P. Li and E. Pfender, "Three Dimensional Modeling of the Plasma Spray Process," J. Thermal Spray Technol., 16, 245 (2007)

[32] M. Vardelle, C. Trassy, A. Vardelle and P. Fauchais, "Experimental Investigation of Powder Vaporization in Thermal Plasma Jets," Plasma Chem. Plasma Process., 11, 185 (1991)

[33] R. M. Young and E. Pfender, "Generation and Behavior of Fine Particles in Thermal Plasmas - A Review," Plasma Chem. Plasma Process., 5, 1 (1985)

[34] M. I. Boulos, J. Jurewicz and J. Guo, Induction plasma synthesis of nanopowders, US patent 8013269 B2.

[35] S. L. Girshick, C. P. Chiu, R. Muno, C. Y. Wu, L. Yang, S. K. Singh, and P.H. McMurry, "Thermal Plasma Synthesis of Ultrafine Iron Particles," J. Aerosol Sci., 24, 367 (1993)

[36] P. Proulx, J. Mostaghimi and M. I. Boulos, "Plasma - Particle Interaction Effects in Induction Plasma Modeling Under Dense Loading Conditions," Int. J. Heat Mass Transfer, 28, 1327 (1985).

[37] P. Proulx, J. Mostaghimi, and M. I. Boulos, "Heating of Powders in r.f. Inductively Coupled Plasma under Dense Loading Conditions," Plasma Chem. Plasma Process., 7, 29 (1987).

[38] www.tekna.com

[39] M. Shigeta, T. Watanabe and H. Nishiyama, "Numerical investigation for nano-particle synthesis in an RF inductively coupled plasma," Thin Solid Films, 457, 192 (2004).

[40] S. Son, M. Taheri, E. Carpenter, V. G. Harris and M. E.
McHenry, "Synthesis of ferrite and nickel ferrite nanoparticles using radiofrequency thermal plasma torch," J. Appl. Phys., 91, 7589 (2002)

[41] J. H. Seo, D. U. Kim, J. S. Nam, S. H. Hong, S. B. Sohn and S. M. Song, "Radio Frequency Thermal Plasma Treatment for Size Reduction and Spheroidization of Glass Powders Used in Ceramic Electronic Devices," $J$. Am. Ceram. Soc., 90, 1717 (2007).

[42] D. Bernardi, V. Colombo, E. Ghedini, A. Mentrelli and T. Trombetti, "3-D Numerical Analysis of Powder Injection in Inductively Coupled Plasma Torches" IEEE Trans. Plasma Sci., 33, 424 (2005).

[43] R. Ye, P. Proulx and M. I. Boulos, "Particle Turbulent Dispersion and Loading Effects in an Inductively Coupled Radio Frequency Plasma," J. Phys. D, Appl. Phys., 33, 2154 (2000).

[44] M. Rahmane, G. Soucy and M. I. Boulos, "Mass transfer in induction plasma reactors," Int. J. Heat Mass Transfer, 32, 2035 (1994).

[45] N.Y. Mendoza-Gonzalez, B.M. Goortani and P. Proulx, "Numerical simulation of silica nanoparticles production in an RF plasma reactor: effect of quench," Mater. Sci. Eng. C, 27, 1267 (2007)

[46] N.Y. Mendoza-Gonzalez, M.El. Morsli and P. Proulx, "Production of Nanoparticles in Thermal Plasmas: A Model Including Evaporation, Nucleation, Coalescence and Fractal Aggregation" J. Therm. Spray Technol., 17, 533 (2008)

[47] D. Harbec, F. Gitzhofer and A. Tagnit-Hamou, "Induction plasma synthesis of nanometric spheroidized glass powder for use in cementitious materials," Powder Technol., 214, 356 (2011)

[48] P. Bushier, H. Schubert, J. Uhlenbusch, and M. Weiss, "Evaporation of Zirconia Powders in a Thermal RadioFrequency Plasma," J. Thermal Spray Technol., 10, 666 (2001)

[49] K. Kawajiri, J. H. Seo, N. Sato, S. H. Hong, and H. Nishiyama, "In-Flight Treatment of Titanium Dioxide Nano Particles Using a DC-RF Hybrid Plasma Flow System"; pp. 32 - 33 in CD-Proceedings of 17 th International Symposium on Plasma Chemistry, Toronto, Canada, August 7 - 12, 2005, Edited by J. Mostaghimi. International Plasma Chemistry Society

[50] T. Ishigaki, Y. Bando, Y. Moriyoshi, and M. I. Boulos, "Deposition from the Vapor Phase During the Induction Plasma Treatment of Alumina Powders," J. Mater. Sci., 28, 4223 (1993).

[51] H. Nishiyama, M. Onodera, J. Igawa and T. Nakajima, "Characterization of In-Flight Processing of Alumina Powder Using a DC-RF Hybrid Plasma Flow System at Constant Low Operating Power," J. Thermal Spray Technol., 18 (4), 593 (2009)

[52] B. M. Goortani, N.Y. Mendoza-Gonzalez and P. Proulx, "Synthesis of $\mathrm{SiO}_{2}$ Nanoparticles in RF Plasma Reactors: Effect of Feed Rate and Quench Gas Injection," Int. J. Chem. React. Eng., 4, A33 (2006).

[53] B. Bora, N. Aomoa R. K. Bordoloi, D. N. Srivastava, H. Bhuyan, A.K. Das and M. Kakati, "Free-flowing, transparent g-alumina nanoparticles synthesized by a supersonic thermal plasma expansion process," Curr. Appl. Phys. doi:10.1016 /j.cap.2011.12.001 (2012) 
[54] M. Kakati, B. Bora, S. Sarma, B.J. Saikia, T. Shripathi, U. Deshpande, A. Dubey, G. Ghosh and A.K. Das, "Synthesis of titanium oxide and titanium nitride nanoparticles with narrow size distribution by supersonic thermal plasma expansion," Vacuum, 82, 833 (2008)

[55] B. Bora, B.J. Saikia, C. Borgohain, M. Kakati and A.K. Das, "Numerical investigation of nanoparticle synthesis in supersonic thermal plasma expansion," Vacuum, 85, 283 (2010)

[56] Ed. by R. d'Agostino, P. Favia, Y. Kawai, H. Ikegami, N. Sato and F. Arefi-Khonsari, Advanced Plasma Technology, Wiley-VCH GmbH \& CO., Weinheim, 2008.

[57] T. W. Ebbensen and P. M. Ajayan, "Large-scale synthesis of carbon nanotubes," Nature, 358, 220 (1992).

[58] S. Iijima and T. Ichihashi, "Single-shell carbon nanotubes of 1-nm diameter," Nature, 363, 603 (1993).

[59] Y. Ando, X. Zhao, K. Hirahara, K. Suenaga, S. Bandow and S. Iijima, "Mass production of single-wall carbon nanotubes by the arc plasma jet method," Chem. Phys. Lett. 323, 580 (2000).

[60] Z. Shi, Y. Lian, F. H. Liao, X. Zhou, Z. Gu, Y. Zhang, S. Iijima, H. Li, K. T. Yue and S. L. Zhang, "Large scale synthesis of single-wall carbon nanotubes by arc-discharge method," J. Phys. Chem. Solids, 61, 1031 (2000).

[61] S.I. Choi, J.S. Nam, J.I. Kim, T.H. Hwang, J.H. Seo and S.H. Hong, "Continuous process of carbon nanotubes synthesis by decomposition of methane using an arc-jet plasma," Thin Solid Films, 506- 507, 244 (2006)

[62] M. Bystrzejewski, A. Huczko, H. lange, W. W. PLotczyk, R. Stankiewicz, T. Pichler, T. Gemming and M.H.Rummeli, "A continuous synthesis of carbon nanotubes by dc thermal plasma jet," Appl. Phys. A, 91, 223 (2008)

[63] K. S. Kim, A. Moradian, J. Mostaghimi, Y. Alinejad, A. Shahverdi, B. Simard and G. Soucy, "Synthesis of SingleWalled Carbon Nanotubes by Induction Thermal Plasma," Nano Res., 2,800 (2009)

[64] K. S. Kim, G. Cota-Sanchez, C. T. Kingston, M. Imris, B. Simard and G. Soucy, "Large-scale production of singlewalled carbon nanotubes by induction thermal plasma," $J$. Phys. D: Appl. Phys., 40, 2375 (2007)

[65] B. Geir and M. Homer, Plasma preparation of Carbon Balck, US Patent 3409403 (1968).

[66] W. R. Norman, Production of Carbon Black Using Plasma-Heated Nitrogen, US Patent 3409403 (1969).

[67] L. Fulcheri, N. Probst, G. Flamant, F. Fabry, E. Grivei and X. Bourrat, "Plasma processing: A step toward the production of new grades of carbon black," Carbon, 40, 169 (2002).

[68] F. Fabry. G. Flamant and L. Fulcheri, "Carbon black processing by thermal plasma. analysis of the particle formation mechanism," Chem. Eng. Sci., 56, 2123 (2001).

[69] K. S. Kim, J. H. Seo, J. S. Nam, W. T. Ju and S. H. Hong, "Production of Hydrogen and Carbon Black by Methane Decomposition Using DC-RF Hybrid Thermal Plasmas," IEEE Trans. Plasma Sci. 33(2), 813 (2005).

[70] S. I. Choi, J. S. Nam and J. H. Seo, "Formation of carbon black by thermal plasma decomposition of methane," $J$. Environmental \& Thermal Eng., 8(3), 1 (2011) (Korean)

[71] K. P. Sreekumar, M. Vijay, T. K. Thiyagarajan, K. Krishnan and P. V. Ananthapadmanabhan, "Reactive Plasma Synthesis of Nanocrystalline Ceramic Oxides," J. Phys.: Conf. Ser., 208012123 (2010).
[72] S. M. Oh and D. W. Park, "Preparation of Ultra-fine Alumina Powders by D. C. Plasma Jet," Korean J. Chem. Eng., 17(3), 299 (2000)

[73] J. Y. Guo, F. Gitzhofer, M. I. Boulos, "Induction plasma synthesis of ultrafine $\mathrm{SiC}$ powders from silicon and $\mathrm{CH}_{4}$," J. Mater. Sci., 30, 5589 (1995).

[74] F. Gitzhofer, "Induction plasma synthesis of ultrafine SiC," Pure \& Appl. Chem., 68, 1113 (1996).

[75] L. Tong and R. G. Reddy, "Synthesis of titanium carbide nano-powders by thermal plasma," Scripta Mater., 52, 1253 (2005).

[76] E. Bouyer, M. Muller, R. H. Henne and G. Schiller, "Thermal plasma processing of nanostructured Si-based ceramic materials," J. Nanopar. Res., 3, 373 (2001)

[77] M. Leparoux, C. Schreuders, J. W. Shin and S. Siegmann, "Induction Plasma Synthesis of Carbide Nanopowders," Adv. Eng. Mater., 7, 349 (2005).

[78] H. Ahn, M. Hur and S. H. Hong, "Synthesis of ultra-fine powders of aluminum nitride by DC plasma spray," $J$. Korean Surface Technology, 29(6), 73 (1996) (Korean)

[79] S. M. Oh and D. W. Park, "Preparation of AlN fine powder by thermal plasma processing," Thin Solid Films, 316, 189 (1998)

[80] Y. H. Hu, "Solid-solution catalysts for $\mathrm{CO}_{2}$ reforming of methane," Catal. Today, 148, 206 (2009)

[81] E. Ruckenstein and Y. H. Hu, "Carbon dioxide reforming of methane over nickel/ alkaline earth metal oxide catalysts," Appl. Catal. A: Gen., 133, 149 (1995).

[82] B. C. Enger, R. Lodeng and A. Holman, "A review of catalytic partial oxidation of methane to synthesis gas with emphasis on reaction mechanisms over transition metal catalysts," Appl. Catal. A: Gen., 346, 1 (2008).

[83] K.O. Christenson, D. Chen, R. Lodeng and A. Holman, "Effect of supports and Ni crystal size on carbon formation and sintering during steam methane reforming," Appl. Catal. A: Gen., 314, 9 (2006)

[84] J. H. Seo, M. Y. Lee and J. S. Kim, "Preparation of NiO$\mathrm{MgO}$ solid solution nano-catalysts for partial oxidation of methane by RF (Radio Frequency) thermal plasma," Surf. Coat. Tech. (submitted).

[85] H. Zea, C. K. Chen, K. Lester, A. Phillips, A. Daty, I. Fonseca and J. Phillips, "Plasma torch generation of carbon supported metal catalysts," Catal. Today, 89, 237 (2004)

[86] G. P. Vissokov, "Some peculiarities of nano-dispersed catalysts synthesized or regenerated in an arc plasma conditions," Catal. Today, 89, 245 (2004)

[87] K. Nishimura, T. Fujii, K. Yubuta and S. Shinozaki, Process for producing oxide coated fine metal particles, US Patent 6582763 B1

[88] K. Nishimura, T. Fujii, K. Yubuta and S. Shinozaki, Fine glass particle containing embedded oxide and process for producing the same, US Patent 6578381 B2

[89] Y. Saito, "Nanoparticles and filled nanocapsules," Carbon, 33, 979 (1995)

[90] Z. Wei, L. Liu, H. Yang, C. Zhang and W. Feng, "Characterization of carbon encapsulated Fe-nanoparticles prepared by confined arc plasma," Trans. Nonferrous Met. Soc. China, 21, 2026 (2011)

[91] T. Oku, T. Kusunose, T. Hirata, R. Hatakeyama, N. Sato, K. Niihara and K. Suganuma, "Formation and structure of 
$\mathrm{Ag}, \mathrm{Ge}$ and $\mathrm{SiC}$ nanoparticles encapsulated in boron nitride and carbon nanocapsules," Diam. Relat. Mater., 9, 911 (2000)
[92] M. Y. Lee, J. S. Kim and J. H. Seo, "RF thermal plasma synthesis of nano-sized IZTO (Indium Zinc Tin Oxide) powders," Thin Solid Films, (submitted) 